\title{
Thyroid metastasis from esophageal adenocarcinoma: a case report and literature review
}

\author{
Shinsei Yumoto', Yoshifumi Baba', Daichi Nomoto', Kazutaka Oozono², Kojiro Eto', Yukiharu Hiyoshi', \\ Yohei Nagai ${ }^{1}$, Masaaki Iwatsuki', Shiro Iwagami ${ }^{1}$, Yuji Miyamoto' ${ }^{1}$, Naoya Yoshida', Yoshiki Mikami ${ }^{2}$ and \\ Hideo Baba ${ }^{1 *}$ (1)
}

\begin{abstract}
Background: The incidence of metastatic spread of gastrointestinal malignancies to the thyroid gland is relatively low and most of these malignancies originate from the colorectum. Thyroid metastasis originating from the esophagus is poorly documented.

Case presentation: A 79-year-old man presented with hoarseness of voice and swallowing difficulty. Eighteen months earlier, he had undergone preoperative chemotherapy (S-1 and oxaliplatin [SOX] therapy) and subtotal esophagectomy with regional lymph nodes dissection and retrosternal narrow gastric tube reconstruction for advanced Barrett's esophageal adenocarcinoma. In the ultrasonographic examination, there was a hypoechoic, indistinct border and heterogeneous nodule in the left lobe of the thyroid gland. Pathological examination of an ultrasound-guided fine-needle aspiration showed adenocarcinoma, supporting a diagnosis of esophageal adenocarcinoma metastases in the thyroid.
\end{abstract}

Conclusion: This is a first case of a patient with thyroid metastasis from Barrett's esophageal adenocarcinoma after subtotal esophagectomy.

Keywords: Thyroid metastasis, Esophageal cancer, Barrett's esophageal adenocarcinoma

\section{Background}

The incidence of metastatic spread of gastrointestinal malignancies to the thyroid gland is relatively low, and most of these malignancies originate from the colorectum [1]. Thyroid metastasis originating from the esophagus is poorly documented. Herein, we report a first case of a patient with thyroid metastasis from Barrett's esophageal adenocarcinoma after subtotal esophagectomy.

\section{Case presentation}

A 79-year-old man presented with hoarseness of voice and swallowing difficulty. Eighteen months earlier, he had undergone preoperative chemotherapy (S-1 and

\footnotetext{
* Correspondence: hdobaba@kumamoto-u.ac.jp

${ }^{1}$ Department of Gastroenterological Surgery, Graduate School of Medical Sciences, Kumamoto University, 1-1-1 Honjo, Chuo-ku, Kumamoto 860-8556, Japan

Full list of author information is available at the end of the article
}

oxaliplatin [SOX] therapy) and subtotal esophagectomy with regional lymph node dissection and retrosternal narrow gastric tube reconstruction for advanced esophageal cancer. The histological examination of the resected specimen revealed Barrett's esophageal adenocarcinoma pStage III (8th UICC TNM classification) (Fig. 1).

Upper gastrointestinal endoscopy showed no abnormal finding including anastomosis site (cervical esophagus and gastric tube). Contrast-enhanced computed tomography (CT) revealed a low-density mass in his left thyroid gland (Fig. 2a). In the ultrasonographic examination, there was a hypoechoic, indistinct border and heterogeneous nodule measuring $16.9 \mathrm{~mm} \times 19.7 \mathrm{~mm} \times 23.9 \mathrm{~mm}$ in the left lobe of the thyroid gland (Fig. 2b, c). Pathological examination of an ultrasound-guided fine-needle aspiration showed adenocarcinoma, supporting a diagnosis of esophageal adenocarcinoma metastases in the thyroid (Fig. 2d). The patient 

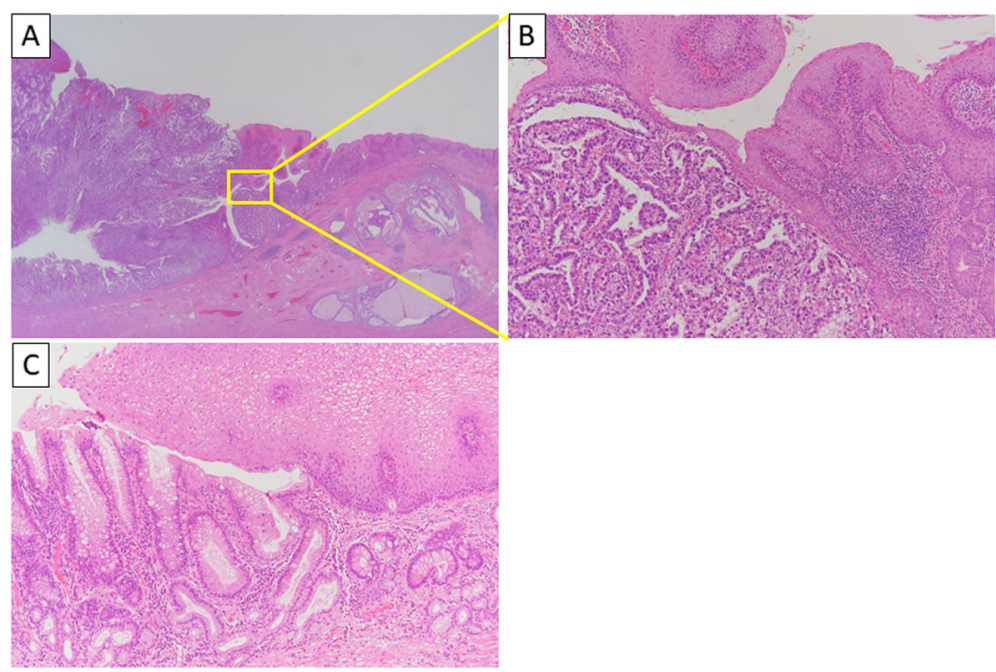

Fig. 1 Hematoxylin-eosin staining of the resected specimen. a Adenocarcinoma is present at the esophagogastric junction $(\times 20$ magnification). $\mathbf{b}$ A moderately differentiated adenocarcinoma is present at the esophagogastric junction ( $\times 200$ magnification). c Distal esophageal squamous epithelium is replaced by specialized columnar epithelium with goblet cells ( $\times 200$ magnification)
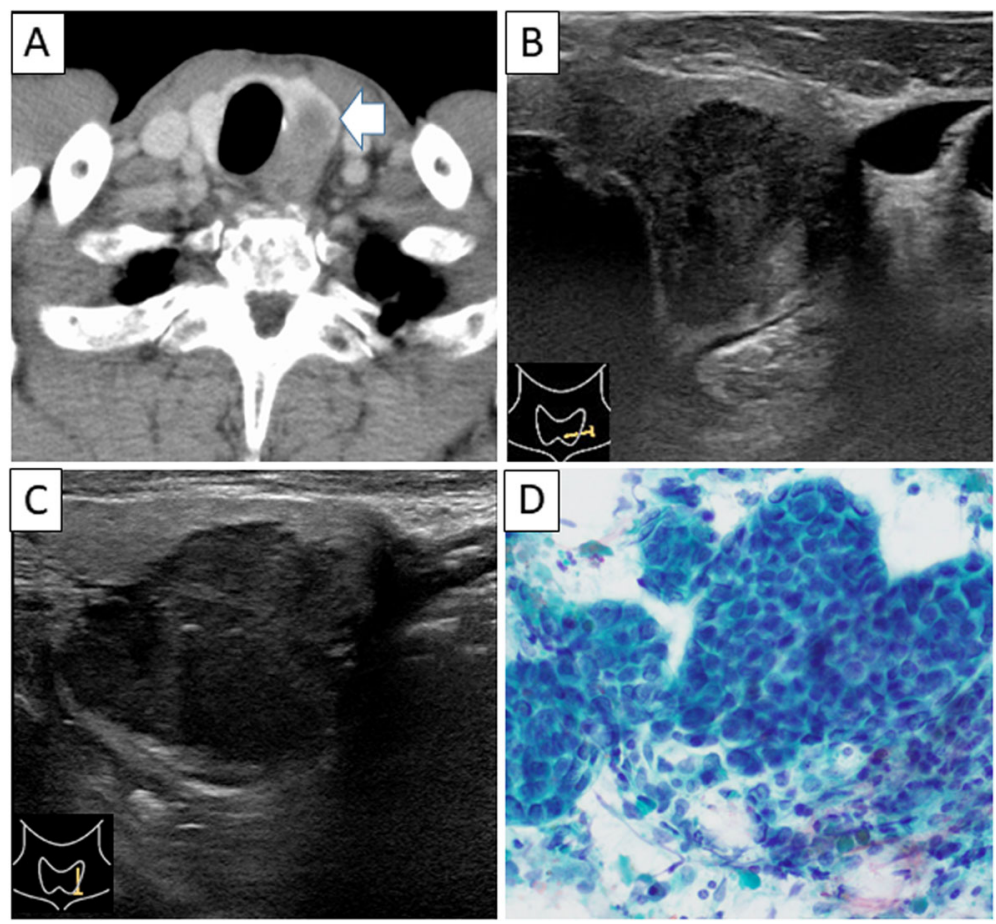

Fig. 2 Imaging and pathological findings. a Contrast-enhanced computed tomography (CT) revealed a low-density mass in left thyroid gland. $\mathbf{b}$ c Ultrasonographic (US) examination showed a hypoechoic, indistinct border and heterogeneous nodule measuring $16.9 \mathrm{~mm} \times 19.7 \mathrm{~mm} \times$ $23.9 \mathrm{~mm}$ in the left lobe of the thyroid gland. $\mathbf{d}$ Pathological examination of an ultrasound-guided fine-needle aspiration showed adenocarcinoma 
commenced chemotherapy with pembrolizumab, combined chemotherapy of docetaxel with cisplatin (CDDP), and 5fluorouracil (5-FU) in a clinical trial. This treatment effectively shrank the tumor after seven courses.

\section{Discussion}

The incidence of intrathyroidal metastases in autopsy series varies from 1.25 to $24.0 \%$ in cancer patients [2, 3]. The metastatic spread of gastrointestinal malignancies to the thyroid gland is relatively rare; the majority originate from the colorectum [1]. Thyroid metastasis from the esophagus has only been reported in eight cases in the English-language literature [1, 4-11]. Importantly, this is the first case of thyroid metastasis from Barrett's esophageal carcinoma.

Table 1 summarizes the clinical features of the eight previously published cases plus our report of thyroid metastasis from esophageal cancer. The age of the patients at presentation was variable, ranging from 32 to 79 years with an average age of 62.1 years. Four out of the eight previously reported cases were treated with thyroidectomy, and the management in the other two cases was not reported [12]. In the postoperative histopathological specimen, six patients showed squamous cell carcinomas and two were adenocarcinomas. Thyroid metastasis of Barrett's adenocarcinoma has never been reported previously in any literature.

Generally, despite being second to the adrenal glands as the most vascular perfused organ in the body [13], the thyroid is rarely considered to be the sole site of metastases in the clinical practice and is usually asymptomatic $[14,15]$. Cichon et al. reported that metastasis to the thyroid only accounts for 2 to $3 \%$ of all thyroid carcinomas identified in the clinical practice [16]. The most common primary sites are the kidney, breast, and lung [17-20]. Direct extension of adjacent primaries, a hematogenous pathway, and lymphatic route for metastatic spread to the thyroid have been estimated $[6,21]$. Czech et al. suggested that the vertebral vein plexus may play an important role in the process of metastases from other organs to the thyroid [19]. Unfortunately, according to a review of the related literature, no case of careful imaging and pathologic evaluation of the most likely route of metastasis in the thyroid has been reported. In our case, the tumor may be considered as a lymphogenous metastasis because there were cervical lymph node metastases in the postoperative histopathological specimen and this lymph node was anatomically close to the thyroid. Of course, we acknowledge that further examination such as autopsy may be useful to clarify the mechanism.

There is no clear consensus on therapeutic strategy for metastatic thyroid cancers from esophageal cancer. Thus, the management is determined on a caseby-case basis [1, 9, 22]. Overall, most patients with metastasis to the thyroid had poor outcomes, with reported 9-month survival after the original diagnosis [23] (Table 1). However, one case was reported where the patient was without evidence of recurrence 4 years after thyroidectomy [5]. In the present case, the patient commenced chemotherapy with pembrolizumab, CDDP, and 5-FU in a clinical trial and experienced a favorable therapeutic effect. If the tumor is still reduced with no new metastatic lesion for some time, we might consider performing surgical resection (i.e., thyroidectomy).

\section{Conclusions}

This case highlights the need for awareness of the possibility of potential metastatic deposits in unexpected sites. A new thyroid mass with a history of cancer, however remote the previous primary cancer was, should be evaluated for the possibility of metastasis. Metastasis should also be strongly considered whenever the histology is unusual for a primary thyroid lesion. Although the prognosis of metastasis in the thyroid is commonly poor, patients may have improved quality of life and longer survival time after early accurate diagnosis and proper treatment.

Table 1 The literature review of cases with thyroid metastasis from esophageal cancer

\begin{tabular}{|c|c|c|c|c|c|}
\hline Source & Age & Sex & Treatment for thyroid & Pathology result & Outcomes \\
\hline Present case & 79 & M & Chemotherapy & Adenocarcinoma & 4 months (alive) \\
\hline Shuangshoti [4] & 58 & M & $\Pi+$ ipsilateral $\mathrm{CL}$ & SCC & 11 months (dead) \\
\hline Yamada et al. [5] & 74 & $\mathrm{~F}$ & $\mathrm{ST}+$ bilateral $\mathrm{CL}$ & SCC & Over 4 years (alive) \\
\hline Basu et al. [6] & 55 & $\mathrm{~F}$ & No data & $\mathrm{SCC}$ & No data \\
\hline Cumbo-Nacheli et al. [7] & 32 & M & No data & Adenocarcinoma & No data \\
\hline Moulick et al. [8] & 66 & M & Chemoradiation & $\mathrm{SCC}$ & No data \\
\hline Chen et al. [9] & 61 & M & Palliative bilateral NT + tracheostomy & $\mathrm{SCC}$ & 11 months (dead) \\
\hline Cheng et al. [10] & 70 & M & Right lobectomy + partial left lobectomy & SCC & 3 months (dead) \\
\hline Reese et al. [11] & 64 & M & None & Adenocarcinoma & No data \\
\hline
\end{tabular}

$\pi$ total thyroidectomy, NT near-total thyroidectomy, ST subtotal thyroidectomy, $C L$ cervical lymphadenectomy, SCC squamous cell carcinoma 


\section{Abbreviations}

SOX: S-1 and oxaliplatin; UICC: Union for International Cancer Control; CT: Computed tomography; CDDP: Cisplatin; 5-FU: 5-Fluorouracil; T: Total thyroidectomy; NT: Near-total thyroidectomy; ST: Subtotal thyroidectomy; CL: Cervical lymphadenectomy; SCC: Squamous cell carcinoma

\section{Acknowledgements}

Not applicable

\section{Authors' contributions}

SY described and designed the article. YB edited the article. YM and KO made a pathological evaluation of the specimens and provided pathological pictures. HB supervised the edition of the manuscript. Other remaining co-authors collected the data and discussed the content of the manuscript. All authors read and approved the final manuscript

\section{Funding}

This study was not funded.

\section{Availability of data and materials}

All data generated or analyzed during this study are included in this published article.

\section{Consent for publication}

Written informed consent was obtained from the patient for publication of this case report and any accompanying images.

\section{Competing interests}

The authors declare that they have no competing interests.

\section{Author details}

'Department of Gastroenterological Surgery, Graduate School of Medical Sciences, Kumamoto University, 1-1-1 Honjo, Chuo-ku, Kumamoto 860-8556, Japan. ${ }^{2}$ Department of Diagnostic Pathology, Kumamoto University Hospital, 1-1-1 Honjo, Chuo-ku, Kumamoto 860-8556, Japan.

Received: 21 March 2019 Accepted: 22 August 2019

Published online: 30 August 2019

References

1. Yoshida A, Imamura A, Tanaka H, Hirano M, Kamma H, Ueno E, Ushio H, Aiyoshi $Y$, Soeda $S$. A case of metastasis from gastric cancer to the thyroid gland. Jpn J Surg. 1989;19:480-4.

2. Berge T, Lundberg S. Cancer in Malmo 1958-1969. An autopsy study. Acta Pathol Microbiol Scand Suppl. 1977;1:235.

3. Nakhjavani MK, Gharib H, Goellner JR, Van Heerden JA. Metastasis to the thyroid gland. A report of 43 cases. Cancer. 1997;79:574-8.

4. Shuangshoti S. Primary carcinomas of esophagus and bronchus with presentation simulating primary carcinoma of thyroid gland. J Med Assoc Thai. 1982:65:38-44

5. Yamada T, Tatsuzawa Y, Yagi S, Fujioka S, Kitagawa S, Nakagawa M, Minato H, Kurumaya H, Matsunou H. Lymphoepithelioma-like esophageal carcinoma: report of a case. Surg Today. 1999;29:542-4.

6. Basu S, Nair N, Borges AM. Squamous cell carcinoma of esophagus masquerading as solitary thyroid nodule. Indian J Cancer. 2005:42:205-7.

7. Cumbo-Nacheli G, De Sanctis JT, Chung MH. Proximal esophageal adenocarcinoma presenting as a thyroid mass: case report and review of the literature. Thyroid. 2007;17:267-9.

8. Moulick A, Guha P, Das A, Das AK. Squamous cell carcinoma of proximal esophagus with simultaneous metastases to thyroid and sternum: a case report and review of the literature. Tanaffos. 2012;11:67-70.

9. Chen ED, Cheng P, Yan XQ, Ye YL, Chen CZ, Ji XH, Zhang XH. Metastasis of distal esophageal carcinoma to the thyroid with presentation simulating primary thyroid carcinoma: a case report and review of the literature. World J Surg Oncol. 2014;12:106.

10. Cheng P, Xiang Y, Chen E, Zou Z, Zhang X. Papillary thyroid microcarcinoma with synchronous asymptomatic advanced esophageal squamous cell carcinoma: a case report and review of the literature. Oncol Lett. 2015:9:731-4.

11. Reese J, Chebolu A, Shen Y, Mihlon F. Case report: Diffuse metastatic infiltration of the thyroid by esophageal adenocarcinoma mimicking nonneoplastic thyroid disease. Radiol Case Rep. 2017;13:108-11.
12. Chen JY, Chen IW, Hsueh C, Chao TC, Gao BR, Lin JD. Synchronous diagnosis of metastatic cancer to the thyroid is associated with poor prognosis. Endocr Pathol. 2015;26:80-6.

13. Wychulis AR, Beahrs $\mathrm{OH}$, Woolner LB. Metastasis of carcinoma to the thyroid gland. Ann Surg. 1964;160:169-77.

14. Chen H, Nicol TL, Udelsman R. Clinically significant, isolated metastatic disease to the thyroid gland. World J Surg. 1999;23:177-80 Discussion 181.

15. Kihara M, Yokomise $H$, Yamauchi A. Metastasis of renal cell carcinoma to the thyroid gland 19 years after nephrectomy: a case report. Auris Nasus Larynx. 2004;31:95-100

16. Cichon S, Anielski R, Konturek A, Barczynski M, Cichon W. Metastases to the thyroid gland: seventeen cases operated on in a single clinical center. Langenbecks Arch Surg. 2006;391:581-7.

17. Pillay SP, Angorn IB, Baker LW. Tumour metastasis to the thyroid gland. S Afr Med J. 1977:51:509-12.

18. Ericsson M, Biorklund $A$, Cederquist $E$, Ingemansson $S$, Akerman M. Surgical treatment of metastatic disease in the thyroid gland. J Surg Oncol. 1981;17:15-23.

19. Czech JM, Lichtor TR, Carney JA, Van Heerden JA. Neoplasms metastatic to the thyroid gland. Surg Gynecol Obstet. 1982;155:503-5.

20. McCabe DP, Farrar WB, Petkov TM, Finkelmeier W, O'Dwyer P, James A. Clinical and pathologic correlations in disease metastatic to the thyroid gland. Am J Surg. 1985;150:519-23.

21. Fujita T, Ogasawara Y, Doihara H, Shimizu N. Rectal adenocarcinoma metastatic to the thyroid gland. Int J Clin Oncol. 2004:9:515-9.

22. Murakami S, Yashuda S, Nakamura T, Mishima Y, lida H, Okano H, Nakano M. A case of renal cell carcinoma with metastasis to the thyroid gland and concomitant early gastric cancer. Surg Today. 1993;23:153-8.

23. Lin JD, Weng HF, Ho YS. Clinical and pathological characteristics of secondary thyroid cancer. Thyroid. 1998;8:149-53.

\section{Publisher's Note}

Springer Nature remains neutral with regard to jurisdictional claims in published maps and institutional affiliations.

\section{Submit your manuscript to a SpringerOpen ${ }^{\circ}$ journal and benefit from:}

- Convenient online submission

- Rigorous peer review

- Open access: articles freely available online

- High visibility within the field

- Retaining the copyright to your article

Submit your next manuscript at $\boldsymbol{\nabla}$ springeropen.com 